\title{
Amazônia legal: análise de convergência da renda municipal com base em um modelo threshold
}

Marcelo Bentes Diniz - Doutor pelo Curso de Pós-Graduação em Economia - CAEN da Universidade Federal do Ceará. Professor da Universidade Federal do Pará.

José Nilo Oliveira Júnior - Doutor pelo Curso de Pós-Graduação em Economia (CAEN) da Universidade Federal do Ceará. Professor da Universidade Federal do Pará.

Roberto Tatiwa Ferreira - Doutor em economia. Professor adjunto do Departamento de Economia Aplicada e do Curso de Pós-Graduação em Economia - CAEN da Universidade Federal do Ceará

Alex Sandro da Paixão - Graduado em Ciências Econômicas pela UFPA.

\section{Resumo}

Este trabalho faz uma análise do processo de convergência de renda entre os municípios da Amazônia Legal no período de 1980 a 2004, no intuito de identificar a existência de clubes de convergência com base em um modelo threshold. Os resultados indicam a formação de seis clubes de convergência, evidenciado-se um processo de convergência entre os clubes extremos. De uma forma geral, o capital humano mostra-se significante para explicar o processo de crescimento dos grupos de municípios mais ricos. Além disso, os resultados indicam que o capital físico foi significativamente negativo para explicar o processo de crescimento econômico da maioria dos clubes de convergência, o que demonstra o papel detrimentoso do investimento público realizado nos municípios da região.

\section{Palavras-chave}

Convergência de renda. Efeito Threshold. Amazônia Legal.

\begin{abstract}
This paper is an analysis of the process of convergence of income between the municipalities of the Legal Amazonia in the period of 1980 to 2004, trying to identify the existence of clubs of convergence using a model threshold. Results indicated for the formation of six clubs of convergence, among them shows a process of convergence between the clubs extremes. In general, human capital proved to be significant in explaining the process of growth of the groups of municipalities richer. The results also indicated that the physical capital was significantly negative for explaining the process of economic growth of most clubs of convergence, demonstrating in this way, a negative role for public investment undertaken in the districts of the region.
\end{abstract}

\section{Keywords}

Income convergence. Threshold effect. Legal Amazon. 


\section{INTRODUÇÃO}

A corroboração empírica de processos de convergência de renda entre países ou entre diferentes recortes espaciais dentro de um mesmo país tornou-se um dos principais temas da agenda de pesquisa sobre crescimento econômico. De fato, os recentes avanços teóricos da moderna teoria de crescimento econômico têm, de forma recorrente, tentado explicar "o que torna alguns países mais ricos que outros", o que tem como corolário verificar se as diferenças existentes entre países, ou grupos de países, reproduzir-se-ão ao longo do tempo.

Isso tem uma importância implícita, pois as melhorias nas condições de vida da população de um país, estado ou município estão quase sempre associadas a um aumento na renda per capita dessa economia (GONDIM; BARRETO, 2004), devido ao fato de os indicadores sociais e econômicos serem altamente correlacionados com o seu nível (RAY, 2004).

Por outro lado, a verificação da hipótese de convergência de renda em recortes espaciais em um mesmo país pode ser uma ferramenta adicional para a promoção de um desenvolvimento regional mais equilibrado. Além do mais, podemse explicar os fatores que justificam a renda e o potencial de desenvolvimento entre as unidades espaciais consideradas.

Segundo Perobelli, Faria e Ferreira (2006), as disparidades regionais podem estar, em parte, relacionadas a questões, por exemplo, de distribuição desigual entre as regiões de um país dos fatores responsáveis pelo crescimento econômico, como recursos naturais, capacitação da mão de obra e acesso a mercados, e, também, a questões de imperfeição na mobilidade dos fatores.

A hipótese de convergência de renda entre os estados ou municípios, segundo a qual as unidades mais pobres da federação cresceriam a taxas mais altas do que as mais ricas, permitiria vislumbrar um futuro melhor para um país que atualmente é marcado por grandes disparidades de renda. Por outro lado, a inexistência de convergência, ou a existência de convergência condicionada a determinado fator (por exemplo, nível de escolaridade, intercâmbio comercial, tecnologia etc.), permitiria orientar os gestores de políticas públicas na direção mais adequada para a redução das desigualdades existentes (GONDIM; BARRETO, 2004).

No Brasil, recentemente têm sido realizados vários estudos a respeito da hipótese de convergência de renda entre os estados, regiões metropolitanas e até mesmo municípios de uma determinada região. Citam-se, por exemplo, Azzoni (1994, 2003), Azzoni et al. (2000), Ferreira (1995), Ferreira e Diniz (1995a, 1995b), Ferreira e Ellery Júnior (1996) e Barossi Filho (2003). No entanto, no que tange à região Norte do Brasil, inexistem trabalhos que dêem atenção específica ao estudo 
da hipótese de convergência de renda nessa área do país, ou no âmbito dos estados que compõem a Amazônia Legal brasileira.

Portanto, objetiva-se neste trabalho realizar um estudo dos clubes de convergência de renda entre os municípios da Amazônia Legal, no período de 1980 a 2004. Pretende-se, dessa forma, testar a hipótese da convergência entre os municípios da Amazônia Legal com base nos trabalhos de Durlauf e Johnson (1995) e de Mankiw, Romer e Weil (1992), usando o modelo Threshold proposto por Hansen $(1997,2000)$.

O modelo de Threshold permite a análise empírica do comportamento de subgrupos de municípios, os quais seriam identificados por dotações iniciais do produto interno bruto (PIB) per capita e convergiriam para diferentes estados estacionários. Por meio do método de análise threshold, torna-se possível a divisão da amostra em subgrupos tendo como base uma função indicadora, a qual utiliza variáveis observáveis que são definidas previamente, além de permitir a utilização de testes estatísticos.

Para a concretização dos objetivos pretendidos, este artigo apresenta, além desta introdução, mais quatro seções. $\mathrm{Na}$ segunda seção será realizada uma revisão de literatura; na terceira será descrita a metodologia e os dados utilizados; na quarta seção serão apresentados os resultados empíricos; por fim, serão apresentadas as conclusões do trabalho.

\section{REVISÃO DA LITERATURA}

Desde o trabalho de Baumol (1986), que concluiu pela existência de convergência entre um grupo de países selecionados, o estudo da convergência entre países tem sido um tema de pesquisa controvertido. De Long (1988) contesta as conclusões de Baumol, apontando, entre outros problemas, a existência de viés de seleção na amostra utilizada dos países analisados, o que fora retificado em Baumol e Wolff (1988), ao reafirmarem a existência de convergência pelo menos para o grupo de países de renda mais alta.

Em um clássico sobre convergência, Barro e Sala-i-Martin (1992) detectam convergência absoluta entre os estados americanos no período de 1840 a 1988; no entanto, em âmbito mundial, com dados cross-section para um grupo de 110 países, somente foi detectada convergência condicional no período de 1960 a 1985. Sala-i-Martin (1996) obtém resultados semelhantes para o mesmo grupo de 110 países no período de 1960 a 1990, porém encontra convergência absoluta para uma subamostra de países da Organização para a Cooperação e o Desenvolvimento Econômico (OCDE), $\beta$-convergência absoluta e condicional, bem como $\sigma$-convergência, para os estados dos EUA, para as prefeituras do 
Japão e para regiões dentro da Alemanha, Reino Unido, França, Itália e Espanha, respectivamente.

Outros resultados destacados pela literatura empírica de crescimento, que atestam convergência de renda em uma amostra selecionada de países, aparecem ainda em Barro e Sala-i-Martin (1995a, 1995b) e em Mankiw, Romer e Weil (1992). Nesses estudos, a começar com o artigo de Mankiw, à medida que se foram desenvolvendo os modelos teóricos, novas variáveis passaram a ser controladas para testar seu poder explicativo sobre a convergência e, por essa via, seu poder de aumentar ou não a velocidade de convergência.

Esses resultados, entretanto, foram contestados tanto de forma teórica, com o surgimento da classe de modelos de crescimento endógeno, como empiricamente, com destaque para o artigo de Pritchett (1997), que, para uma amostra ampla de países, atesta a existência, no período de 1870 a 1990, não de convergência como os modelos teóricos previam, mas de um grande processo de divergência de renda entre os países.

Com relação à classe de modelos de crescimento endógeno, destacam-se os trabalhos de Lucas (1988) e de Romer (1986), em que consideram os efeitos de spillover do capital humano. O primeiro inclui, na função de produção neoclássica, o insumo capital humano, concebido como o estoque de conhecimento acumulado da população, enquanto o segundo abandonou a hipótese de concorrência perfeita e retornos decrescentes dos fatores e postulou a existência de externalidades advindas do aprendizado adquirido no processo produtivo - learning by doing. Nos dois casos, como chama a atenção Capolupo (1998), a possibilidade de retornos constantes ou crescentes faz com que o "mecanismo por trás da convergência desapareça". Além disso, os modelos de crescimento endógeno com P\&D, como em Aghion e Howitt (1992), Grossman e Helpman (1991) e Romer (1990), reforçam esse argumento, assentado no fato de que a dinâmica continuada das inovações precisa criar algum mecanismo de poder de monopólio, o que poderia aumentar o gap entre os países.

A literatura mais recente sobre crescimento econômico tem apontado a qualidade das instituições de um país como o principal responsável pelo crescimento. Várias são as tentativas de mensurar o nível de democracia, o respeito ao direito de propriedade, a agilidade do Poder Judiciário, a eficiência do sistema financeiro, entre outras variáveis institucionais. Por exemplo, Acemoglu et al. (2001), Hall e Jones (1999), Jonhson e Robinson (2004) e Rodrick et al. (2002) encontraram evidências empíricas que corroboram a hipótese segundo a qual a qualidade institucional é a mais relevante causa do crescimento econômico.

Para o Brasil, Lau et al. (1993) afirmam que as quatro principais variáveis 
relacionadas ao crescimento econômico do produto agregado são o capital, o trabalho, o capital humano, o progresso tecnológico e o tempo. Baseando-se em dados dos estados brasileiros de 1970 e 1980, os autores estimaram uma metafunção de produção agregada. Introduziram o capital humano, quantificado como o número médio de anos de educação formal por pessoa da força de trabalho, explicitamente como uma variável na função de produção agregada. Também introduziram uma tendência de tempo para capturar o efeito do progresso técnico. Segundo os autores, algum melhoramento no insumo não capturado pela variável capital humano deveria ser refletido no progresso técnico.

Ferreira e Diniz (1995), em um trabalho sobre convergência de renda per capita estadual no Brasil, abordaram a ideia de convergência absoluta a partir da equação proposta por Baumol (1986), obtendo o sinal dos parâmetros conforme o esperado e, então, concluindo que houve $\beta$-convergência entre os estados brasileiros. Os autores consideraram como fatores responsáveis pelo processo de convergência o desenvolvimento e a ampliação da infraestrutura, o movimento das fronteiras agrícola e mineral, a ação direta do Estado em termos de investimento e concessão de subsídios e incentivos fiscais, a crise econômica e política do Rio de Janeiro, a reversão da polarização industrial da área metropolitana de São Paulo, os movimentos migratórios e as alterações na distribuição regional da população. Em relação à determinação de $\sigma$ - convergência, partindo da premissa de que a distribuição de renda igualitária entre os estados exigiria que coubesse a cada estado uma proporção de renda interna equivalente a sua participação relativa na população do país, os autores utilizaram um indicador que representava a razão entre a participação da população e da renda do estado na do país. Como tendência geral, para uma análise dos anos de 1970, 1975, 1980 e 1985, Ferreira e Diniz (1995) concluíram que o grau de desigualdade estaria diminuindo ao longo do período considerado, embora uma extrema desigualdade ainda prevalecesse em 1985.

Azzoni et al. (2000) apresentam evidências da controvérsia das rendas dos estados brasileiros no período de 1981 a 1996. Dessa forma, propuseram-se a estimar a variação no rendimento per capita das famílias dos estados brasileiros como função da geografia, do estado e da família, visando com isso capturar não somente as características individuais das famílias na convergência ou divergência de renda per capita (ao longo das linhas do modelo neoclássico), mas também aquelas características espaciais e geográficas.

Os resultados indicaram que as variáveis geográficas são importantes para explicar as diferenças nos níveis de renda e no crescimento econômico dos estados brasileiros. Além disso, os autores chegaram à conclusão de que não existia evidência de convergência absoluta entre os estados brasileiros no período 
analisado. Os resultados indicavam alta velocidade de convergência de renda entre os estados brasileiros somente depois de serem consideradas diferenças na geografia, no capital humano, na participação da força de trabalho, na infraestrutura e nas condições de desenvolvimento humano.

Alves e Fontes (2000) investigaram a constituição de clubes de convergência entre os municípios mineiros no período de 1985 a 1997. Para tanto, os autores agregaram os municípios mineiros com base num determinado grau de similaridade em um contexto multivariado, por meio da técnica de análise de cluster. Para isso, levaram em consideração um conjunto de variáveis econômicas e sociais representativas do nível de capital humano, distribuição de renda, pobreza, dimensão da economia e renda e o uso de variáveis dummies regionais. O teste para a verificação empírica da beta-convergência de renda entre os municípios mineiros seguiu Barro e Sala-i-Martin (1992), numa análise cross-section, apresentando o nível inicial de PIB por habitante como principal variável explicativa e a taxa de crescimento per capita das rendas municipais como variável dependente. A ocorrência de convergência em um grupo significaria que ele seria um clube de convergência. Tal fato foi verificado pelos autores, na medida em que foram identificados nove clubes de convergência com base no critério beta-convergência.

Uma vez que os autores constataram certa tendência para a convergência das rendas intragrupos, interessaram-se também em saber se havia um movimento de convergência entre os clubes de convergência. Os testes revelaram-se positivos, porém a uma velocidade mais lenta do que a da convergência intragrupos.

Menezes e Azzoni (2000), em uma análise de dados de painel, objetivaram calcular a velocidade de convergência entre as regiões metropolitanas brasileiras usando dados da renda real e nominal para o período de 1981 a 1996. Dito isso, em relação aos resultados, os autores compararam os coeficientes da velocidade de convergência dos dados reais e nominais, assim como dos estimadores de Mínimos Quadrados Ordinários (MQO) e de Efeito Fixo (EF), analisando a diferença entre eles. Conforme os autores, quando se comparam os resultados dos estimadores de MQO, para dados nominais e reais em cross-section e em dados de painel, verifica-se o seguinte: no primeiro caso, rejeita-se a existência de convergência absoluta, enquanto, no segundo, não se rejeita, a 5\%; entretanto, nos dois casos, não se identificam diferenças significativas quando se trabalha com dados de renda real ou nominal.

Observando os coeficientes da velocidade de convergência, os autores destacaram que, para a amostra completa, os resultados quase não se alteram quando são comparados com base nas rendas reais e nominais. No entanto, a velocidade de convergência apresentava aumento após o controle por efeito fixo, 
reduzindo-se número de anos necessários para a metade da convergência, de 9 para aproximadamente 2 anos. Outro fato é que a velocidade de convergência fica reduzida após o deflacionamento da renda na estrutura de dados em painel. Desse modo, pode-se deduzir que o diferencial de renda per capita, entre as regiões metropolitanas brasileiras, seria explicado principalmente pela existência de efeitos fixos que dificultam a convergência absoluta entre as regiões.

Souza e Porto Júnior (2002) buscaram debater o tema convergência de renda entre os estados do Brasil e introduzir resultados sobre os municípios nordestinos. Os autores empregaram testes que estudam o comportamento dinâmico da renda per capita e da distribuição de renda como um todo. Aplicaram o teste de Drennan e Lobo (1999), o qual se fundamenta na probabilidade condicional da renda per capita e permite evitar o problema da falácia de Galton. Além do mais, empregaram o método de Quah (1993) para os dados de renda per capita do Brasil. Após aplicação para a região Nordeste, ambas as metodologias chegaram à conclusão de que não se corrobora a hipótese de convergência entre os municípios nordestinos. A análise foi ampliada para os estados brasileiros, e os testes apontaram para a formação de blocos de renda per capita distintos, típicos de polarização.

Laurini, Andrade e Pereira (2003) analisaram a evolução da distribuição da renda relativa per capita para os municípios brasileiros no período de 1970 a 1996. As análises basearam-se em metodologias não paramétricas, sem assumirem distribuições de probabilidade e formas funcionais para os dados. Os autores realizaram dois testes de convergência, um teste para $\sigma$-convergência via boostrap e outro de $\beta$-convergência usando smoothing splines para as regressões de crescimento. Segundo os autores, as evidências observadas demonstraram a necessidade de se modelar a dinâmica da renda dos municípios brasileiros como um processo de clubes de convergência, usando-se a metodologia de matrizes de transição e núcleo estocástico. Os resultados refletiram a formação de clubes de convergência. Ademais, os resultados confirmaram a existência de dois clubes de convergência: um clube de baixa renda, formado pelos municípios das regiões Norte e Nordeste, e outro clube de alta renda, formado pelos municípios das regiões Centro-Oeste, Sudeste e Sul.

Pôrto Júnior e Ribeiro (2003) realizaram uma análise sobre a dinâmica espacial da renda per capita e do crescimento econômico entre os municípios do Nordeste do Brasil no período de 1970 a 1996. Para tal análise, os autores aplicaram o método de Quah (1993) para os dados de renda per capita dos municípios nordestinos. Ao contrário de trabalhos anteriores, os resultados apontaram para a formação de clubes de convergência entre as regiões nordestinas e a polarização entre ricos e pobres, além de negar a hipótese de convergência absoluta. Segundo 
os autores, entre os 1.372 municípios da região nordestina existe uma tendência de longo prazo de concentração em rendas médias/baixas, que pode ser interpretada como clubes de convergência - um clube de renda abaixo da média com $77 \%$ dos municípios, um grupo de renda média contendo $10 \%$ dos municípios e um grupo muito pobre com os $13 \%$ restantes.

Gondim, Barreto e Carvalho (2007) verificaram os principais condicionantes dos clubes de convergência no Brasil. Para tanto, utilizaram a metodologia de Quah para a renda condicionada de estados e municípios entre 1970 e 2000 dividida em nove classes de tamanho fixo. Os condicionantes utilizados foram a localização geográfica, a escolaridade, a abertura comercial e a desigualdade de renda. Os resultados, em geral, indicam a formação de dois clubes de convergência, o maior formado por estados com renda baixa e um pequeno formado por estados com renda alta, no âmbito tanto estadual como municipal. Quanto aos condicionantes, os resultados indicam, tanto para os estados como para os municípios, que o nível de escolaridade e a localização geográfica seriam fatores importantes na formação desses clubes. Por outro lado, a maior integração ao comércio internacional e a desigualdade da renda sinalizam não terem influência sobre a desigualdade regional no Brasil.

Oliveira Junior, Castelar e Ferreira (2007) investigaram a hipótese de clubes convergência da renda agrícola entre as microrregiões do Brasil usando dados dos censos agrícola de 1970 a 1995. Para tal, utilizaram um modelo threshold, o qual utiliza uma função indicadora para dividir a amostra tanto quanto for necessário, devido à heterogeneidade das unidades observadas. Os resultados apontam a formação de três clubes de convergência: um clube mais rico formado por microrregiões do Sul e do Sudeste, um clube intermediário formado, principalmente, pelas microrregiões do Norte e do Centro-Oeste e, por fim, um clube mais pobre formado pelas microrregiões do Nordeste. Os resultados também mostraram que o capital físico é mais importante que o capital humano na explicação do processo de crescimento da agricultura brasileira.

Pode-se constatar, nos diversos trabalhos sobre a hipótese de convergência para o Brasil, bem como nos diversos períodos de análise, que existem algumas conclusões coincidentes. Observa-se, entre os estados brasileiros, que o processo de convergência é inexistente ou instável e fraco. Em relação aos municípios, não obstante o pequeno número de trabalhos, a literatura aponta para a divergência e a polarização. Ainda, os resultados para clubes de convergência indicam a formação de dois polos, de estados ou de municípios, com características socioeconômicas diferentes. Percebe-se, assim, que, ao contrário dos países desenvolvidos, as desigualdades regionais brasileiras são extremamente persistentes. 


\section{METODOLOGIA}

\subsection{Referencial teórico}

O modelo utilizado é baseado em Mankiw, Romer e Weil (1992), o qual segue o modelo de Solow. O modelo considera uma economia fechada, que possui somente um setor de produção e utiliza capital físico, trabalho e capital humano como principais fatores de produção. O capital humano é entendido como as capacidades, competências e conhecimentos dos trabalhadores individuais. Portanto, nesse ponto de vista, considera-se todo capital humano como um bem exclusivo e competitivo e assume-se a hipótese de rendimentos constantes de escala na função de produção Cobb-Douglas.

Dito isso, tem-se a seguinte descrição do modelo:

1- Função de produção: $Y_{t}=K_{t}^{\alpha} H_{t}^{\beta}\left[A_{t} L_{t}\right]^{1-\alpha-\beta}$,

$0<\alpha, \beta, \alpha+\beta>1$,

onde:

$\mathbf{Y}$ representa o produto e $\mathbf{K}$ representa o estoque de capital físico que é acumulado por meio do investimento em bens de capital.

O investimento em bens de capital corresponde a $S_{K}=S_{K} Y_{t}, \quad 0<s_{K}<1$ , em que $S_{K}$ é a fração do produto destinada ao capital físico.

$\mathrm{H}$ representa o estoque de capital humano que é acumulado por meio do investimento em educação.

O investimento em educação corresponde a $S_{H}=S_{H} Y_{t}, \quad 0<s_{H}<1$, em que $S_{H}$ é a fração do produto destinada ao capital humano.

Grosso modo, a poupança divide-se na formação de capital humano e na formação de capital físico e na depreciação de capital físico e na depreciação de capital humano que são, respectivamente:

$$
\delta_{K} K_{t}, \quad 0<\delta_{K}<1 \text { e } \delta_{H} H_{t}, \quad 0<\delta_{H}<1
$$

2- As equações de acumulação de capital físico e capital humano são, respectivamente: $K=s_{K} Y_{t}-\delta_{K} K_{t}$ e $H=s_{H} Y_{t}-\delta_{H} H_{t}$.

Do mesmo modo que no modelo de Solow, o progresso técnico e o trabalho crescem, respectivamente, a taxas constantes e exógenas.

A é o índice de produtividade total dos fatores; resume o estado atual do conhecimento teórico, o também chamado progresso técnico. Sua taxa de crescimento é uma constante exógena, $\chi$.

$\mathbf{L}$ representa a força de trabalho ou o trabalho. Sua taxa de crescimento é uma constante exógena $\eta$. 
Dado que se assumem rendimentos constantes de escala, podem-se descrever as taxas de crescimento do estoque de capital físico e humano por unidade de trabalho eficiente, respectivamente, como: e

$$
\frac{\dot{h}}{h}=s_{H} k^{\alpha} h^{\beta-1}-\left(\eta+\chi+\delta_{H}\right)
$$

Resolvendo o sistema, obtém-se a seguintģlei de formaçãa:

$$
L n y^{*}=\frac{\alpha^{2}}{1-\alpha-\beta} h \frac{s_{K}}{\eta+\chi+d}+\frac{\beta}{1-\alpha-\beta} h \frac{s_{H}}{\eta+\chi+d}
$$

onde: $d=\delta_{K}=\delta_{H}$.

Considerando-se que a equação (2) acima está escrita em termos de produto por unidade de trabalho eficiente, que não é diretamente observável, torna-se conveniente reescrevê-la em termos de produto por unidade de trabalho:

$$
\frac{1}{w} \operatorname{Ln} Q_{t+w}=\left(\operatorname{Ln} Q_{t}-\operatorname{Ln} A_{t}\right) \frac{e^{-b(t+w)}}{w}+\operatorname{Ln} y^{*} \frac{1-e^{-b(t+w)}}{w}+\frac{1}{w}\left(\operatorname{Ln} A_{t}+h \chi_{t+w}\right)
$$

1 Por fim, conforme Destinobles (2005), subtraindo-se em ambos os lados $\left(\frac{1}{w} \operatorname{Ln} Q_{t}\right)$, obtém-se a equação de convergência condicional do modelo de Mankiw, Romer e Weil (1992), expressa abaixo:

$\frac{1}{w}\left(\operatorname{Ln} Q_{t+w}-\operatorname{Ln} Q_{t}\right)=$

$h \chi_{t+w}\left[\frac{1}{w}+\frac{1-e^{-b(t+w)}}{t+w}\right]\left[\frac{\alpha}{1-\alpha-\beta} \operatorname{Lns}_{K}+\frac{\beta}{1-\alpha-\beta} \operatorname{Lns}_{H}-h(\eta+\chi+d)\left(\frac{\alpha+\beta}{1-\alpha-\beta}\right)-\operatorname{Ln} Q_{t}+\operatorname{Ln} A_{t}\right]$ (4).

Conforme Durlauf e Johnson (2005), a equação acima representa uma versão restrita do modelo de crescimento de Solow, tanto quanto coloca restrições não lineares nos coeficientes das regressões. Contudo, quando se assume o mesmo valor de b (a taxa de convergência em direção ao estado estacionário) para todas as observações em estudo - neste caso, os municípios da Amazônia Legal -, o modelo seria levado para uma versão não restrita do modelo neoclássico de Solow para o produto por trabalhador, e a equação pode ser expressa da seguinte forma: 


$$
\mathrm{h}(Q)_{i, T+w}-\mathrm{h}(Q)_{i, T}=\beta_{0}+\beta_{1} \mathrm{~h}(Q)_{i, T}+\beta_{2} \ln \left(s_{K}\right)_{i}+\beta_{3} \ln \left(s_{H}\right)_{i}-\beta_{4} \ln \left(\eta_{i}+\chi+d\right)
$$

onde i representa os municípios e t representa o tempo.

Assim, a evidência de convergência poderia ser relatada para um valor negativo de $\beta_{1}$ da equação acima. Ou seja, isso corresponderia à intuição de que ocorre convergência, na qual economias com produto per capita inicial mais baixo experimentam um maior crescimento econômico comparado com aquelas economias com maior produto per capita inicial.

Nesse contexto, como existe a possibilidade de que a hipótese de convergência entre todos os municípios da Amazônia Legal não seja relatada, convém utilizar-se de métodos para a identificação de múltiplos estados de equilíbrio, os quais possibilitariam testar a convergência para grupos de dentro da amostra.

\subsection{Múltiplos estados de equilíbrio}

$\mathrm{Na}$ literatura contemporânea, comumente observam-se alguns modelos que são baseados no pressuposto de que poderiam existir funções de produção agregada que não seriam côncavas, permitindo, assim, diferentes equilíbrios de estado estacionário a longo prazo para diferentes condições iniciais (DURLAUF; JOHNSON, 2005; OLIVEIRA JUNIOR; CASTELAR; FERREIRA, 2007). Entre esses modelos, encontra-se o de Azariadis-Drazen (1990), que introduz um efeito limiar (threshold) no processo de acumulação de capital físico ou humano, de forma que a função de produção seria expressa por:

$$
\begin{aligned}
& Y_{i, t}=K_{i, t}^{\alpha_{j}} H_{i, t}^{\beta_{j}}\left(A_{t} L_{i, t}\right)^{1-\alpha_{j}-\beta_{j}} \\
& \text { onde: } \alpha_{j}=\left\{\begin{array}{cc}
\alpha_{1} \& & K_{i, t}<\widetilde{K}_{t}, \\
\alpha_{2} \text { caso } & \text { contrário }
\end{array} \text { e } \beta_{j}=\left\{\begin{array}{cc}
\beta_{1} \& & H_{i, t}<\widetilde{H}_{t}, \\
\beta_{2} \text { caso } & \text { contrário }
\end{array}\right.\right.
\end{aligned}
$$

Considerando-se as equações acima com as propriedades da nãoconcavidade $^{1}$ da função de produção, chega-se à equação (7) abaixo, que representa as leis de formação e de geração de múltiplos estados estacionários para particulares valores de thresholds de $\widetilde{H}_{t}$ e $\widetilde{K}_{t}$.

\footnotetext{
1 A não concavidade da função de produção estaria intimamente relacionada com a heterogeneidade observada entre os municípios, o que leva à possibilidade de existência de múltiplos estados estacionários.
} 


$$
\begin{gathered}
\mathrm{h}(Y / L)_{i, T+w}-\mathrm{h}(Y / L)_{i, T}=\chi_{T+w}+\left(1-e^{-b_{i, T+w}}\right)\left(\Theta_{j}+\frac{\alpha_{j}}{1-\alpha_{j}-\beta_{j}} \ln \left(s_{K}\right)_{i}+\right. \\
\left.\frac{\beta_{j}}{1-\alpha_{j}-\beta_{j}} \ln \left(s_{H}\right)_{i}-\frac{\alpha_{j}+\beta_{j}}{1-\alpha_{j}-\beta_{j}} \ln \left(n_{i}+\chi+d\right)-\ln (Y / L)_{i, T}\right)
\end{gathered}
$$

(7),

onde $\mathrm{T}$ e $\mathrm{T}+\mathrm{w}$ representam o intervalo de tempo, $\mathrm{i}$

representa os municípios e $\left.b_{i, j}=\left(1-\alpha_{j}-\beta_{j}\right) \eta_{i}+\chi+d\right)_{\mathrm{e}}$ $\Theta_{j}=1 /\left(1-\alpha_{j}-\beta_{j}\right)-\mathrm{h} A_{T}-\chi_{T}$.

Assim, os municípios da Amazônia Legal seguiriam algumas distintas leis de formação do modelo de Solow, de acordo com o relacionamento entre $\left(K_{i, t}, H_{i, t}\right)$ e $(\widetilde{K}, \widetilde{H})$. Além disso, o modelo de Azariadis-Drazen (1990), demonstrado acima, estimula e sustenta a análise empírica do comportamento de subgrupos de municípios, os quais seriam identificados por dotações iniciais do valor da produção per capita, seguindo diferentes tipos de regressões de crescimento de Solow (DURLAUF; JOHNSON, 1995; OLIVEIRA JUNIOR; CASTELAR; FERREIRA, 2007).

\subsection{Modelo Threshold}

Dito isso, neste trabalho, a metodologia estatística utilizada para proceder à análise de threshold e identificar os múltiplos estados de equilíbrio segue Hansen (2000), que desenvolveu um modelo que permite a divisão da amostra baseada em uma função indicadora, a qual utiliza variáveis observáveis, definidas previamente como determinantes na divisão da amostra em subgrupos.

As equações a seguir descrevem o modelo e as técnicas de inferência estatística necessárias para a análise empírica proposta neste trabalho.

O modelo de regressão com efeito threshold pode ser expresso como:

$$
\begin{array}{ll}
y_{i}=\theta_{1}^{\prime} x_{i}+e_{i}, & q_{i} \leq \gamma \\
y_{i}=\theta_{2}^{\prime} x_{i}+e_{i}, & q_{i}>\gamma
\end{array}
$$


onde $q_{i}$ é a variável threshold, a qual é usada para dividir a amostra em dois grupos, que podem ser chamados classes ou regimes. A variável aleatória $e_{i}$ é o erro de regressão.

Para escrever o modelo em uma única equação, define-se a variável dummy $d_{i}(\gamma)=I\left\{q_{i} \leq \gamma\right\}$, em que $I\{\cdot\}$ é uma função indicadora, e faz-se $x_{i}(\gamma)=x_{i} d_{i}(\gamma)$, tal que:

$$
y_{i}=\theta_{2}^{\prime} x_{i}+\delta_{n}^{\prime} x_{i}(\gamma)+e_{i}
$$

onde $\delta_{n}=\theta_{2}-\theta_{1}$.

A equação (10) pode ser representada na forma matricial. Isto é, Y e $e$ são vetores (n x 1), $\mathbf{X}$ e $X_{\gamma}$, matrizes com dimensão (n x m). Então, a equação (10) pode ser escrita como:

$$
Y=X \theta+X_{\gamma} \delta_{n}+e
$$

Os parâmetros da equação acima $\left(\theta, \delta_{n}, \gamma\right)$ podem ser estimados por mínimos quadrados. Definindo-se $S_{n}(\theta, \delta, \gamma)=\left(Y-X \theta-X_{\gamma} \delta\right)^{\prime}\left(Y-X \theta-X_{\gamma} \delta\right)$ como a função de soma de quadrados dos erros, por definição, os estimadores de mínimos quadrados $\hat{\theta}, \hat{\delta}, \hat{\gamma}$ minimizam a soma acima. Nesse processo, assume-se que $\gamma$ é restrito a um conjunto limitado $[\gamma, \bar{\gamma}]=\Gamma$.

Condicionando-se os parâmetros da equação (11) aos valores de $\gamma$, obtêmse os estimadores de mínimos quadrados condicionados, $\hat{\theta}(\gamma)$ e $\hat{\delta}_{n}(\gamma)$, por meio da regressão de $\mathbf{Y}$ em $X_{\gamma}^{*}=\left[X X_{\gamma}\right]$. Assim, $S_{n}(\theta, \delta, \gamma)$ pode ser escrita na forma concentrada:

$$
S_{n}(\gamma)=S_{n}(\hat{\theta}(\gamma) \hat{\delta}(\gamma) \gamma)=Y^{\prime} Y-Y^{\prime} X_{\gamma}^{*}\left(X_{\gamma}^{*} X_{\gamma}^{*}\right)^{-1} X_{\gamma}^{*} Y
$$

Para encontrar o valor de $\hat{\gamma}$ que minimiza a equação (12), deve-se realizar uma varredura sobre os valores de $\gamma$, i.e. sobre $\Gamma$, tal que

$$
\hat{\gamma}=\underset{\gamma \in \Gamma}{\arg \min } S_{n}(\gamma),
$$

onde $\Gamma_{n}=[\gamma, \bar{\gamma}] \cap\left\{q_{1}, \cdots, q_{n}\right\}, \Gamma_{e}\left\{q_{1}, \cdots, q_{n}\right\}$ é a amostra de variáveis candidatas à variável threshold. Após a determinação de $\hat{\gamma}$, as estimativas de MQO de $\theta$ e $\gamma$ são dadas por $\hat{\theta}=\hat{\theta}^{\prime}(\hat{\gamma})$ e $\hat{\delta}=\hat{\delta}(\hat{\gamma})$.

Em geral, a estimação do intervalo de confiança no modelo threshold é encontrada por meio da inversão da estatística de Wald ou da estatística t. No entanto, como no modelo em questão o parâmetro $\gamma$ não é identificado, a estatística de Wald tem suas propriedades de pequenas amostras prejudicadas ${ }^{2}$. A

2 Para mais informações, ver Dufour (1997). 
estratégia utilizada por Hansen é baseada na estatística de verossimilhança $R{ }_{n}(\gamma)$.

Para elaborar regiões de confiança com base em $R_{n}(\gamma)$, define-se $\mathbf{C}$ como o nível de intervalo de confiança assintótico $(C=0, \mathfrak{9}), c=c_{\xi}(C)$ como o valor crítico do intervalo $\hat{\Gamma}=\left\{\gamma: \boldsymbol{R}_{n}(\gamma) \leq c\right\}$. Um método gráfico para encontrar a região de $\hat{\Gamma}$, sob a hipótese de homocedasticidade, é grafar a taxa de verossimilhança $R_{n}(\gamma)$ contra $\gamma$ e traçar uma linha horizontal em c. Equivalentemente, pode-se grafar a soma dos resíduos dos erros quadrados, $S_{n}(\gamma)$, contra $\gamma$ e traçar uma reta em $S_{n}(\hat{\gamma})+\hat{\sigma}^{2} c$.

Observe-se que se a hipótese de homocedasticidade é rejeitada, a estatística de verossimilhança pode ser redefinida como:

$$
R_{n}^{*}(\gamma)=\frac{R_{n}(\gamma)}{\hat{\eta}^{2}}=\frac{S_{n}(\gamma)-S_{n}(\hat{\gamma})}{(13) . \hat{\sigma}^{2} \hat{\eta}^{2}}
$$

Por fim, após o modelo threshold identificar a existência de múltiplos regimes, serão estimadas regressões por MQO para cada grupo com características socioeconômicas diferentes ${ }^{3}$.

\subsection{Análise empírica}

O modelo empírico que será usado para a análise da hipótese de convergência é obtido pressupondo-se o mesmo valor de $b_{i}$ para todos os municípios da Amazônia Legal, o que resulta na equação para o produto per capita abaixo.

$\mathrm{h}(Y / L)_{i, 2004}-\mathrm{h}(Y / L)_{i, 1980}=\beta_{0}+\beta_{1} \mathrm{~h}(Y / L)_{i, 1980}+\beta_{2} \mathrm{~h}\left((\text { capital físico })_{i, 2004}\right)+$

$$
\beta_{3} \mathrm{~h}(\text { capital humano })_{i}-\beta_{4} \mathrm{~h}\left(n_{i}+\chi+d\right)+\varepsilon_{i}
$$

onde $\varepsilon \sim N\left(0, \Omega_{\varepsilon}\right)$ é o erro da regressão. Assume-se, seguindo Mankiw, Romer e Weil (1992), que $\chi=0,0$ e $d=0,0$

Como já dito anteriormente, a evidência de convergência é relatada para um sinal negativo de $\beta_{1}$. Vale salientar que a taxa de convergência em estado estacionário é dada por $b_{i}=\mathbf{h}\left(1+\beta_{1}\right) / T+w$.

Os dados utilizados neste trabalho são dados em cross-section para 237 municípios da Amazônia Legal ${ }^{4}$, de acordo com a definição do Instituto de Pesquisa

3 Foram empregadas estimações com correções para heterocedasticidade. Para mais informações, ver Durlauf e Johnson (1995).

4 Vale salientar que o número total de municípios, conforme o IPEA, seria de 763; no entanto, devido à falta de dados para proxies como o PIB de 1980, além de outras variáveis, tiveram de ser retirados da amostra 526 municípios. Muitos municípios não existiam em 1980, já que foram 
Econômica Aplicada (IPEA), nos anos de 1980, 1996, 2000, 2001, 2002, 2003 e 2004, os quais foram coletados no IPEADATA (INSTITUTO DE PESQUISA ECONOMICA APLICADA, 2008). As variáveis utilizadas são descritas abaixo: $(Y / L)_{i, 1980}=$ Produto Interno Bruto $^{5}$ per capita para o município i, no ano de 1980;

(capital físico $)_{i}=$ foi utilizada como proxy para capital físico a fração média do Produto Interno Bruto correspondente ao Fundo de Participação Municipal de cada município i para os anos de 1996, 2000, 2001, 2002, 2003 e 2004;

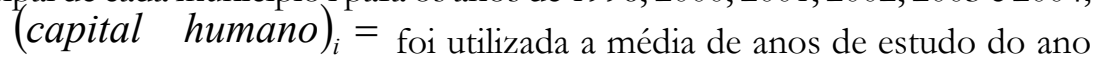
2000 do município i como proxy, que compreende a razão entre o somatório do número de anos de estudo completados pelas pessoas que têm 25 ou mais anos de idade e o número de pessoas nessa faixa etária;

$(n)_{i}=$ compreende a taxa de crescimento da população no período de 1980 a 2004 do município $\mathbf{i}$.

\section{RESULTADOS EMPÍRICOS}

\subsection{Estimação do efeito Threshold}

Nos testes empíricos realizados no presente trabalho, a decisão de dividir os dados foi baseada nas evidências do efeito threshold, em que se considerou a variável do Produto Interno Bruto per capita de 1980 como candidata a variável threshold do modelo. Conforme Oliveira Junior, Castelar e Ferreira (2007), as evidências para o efeito threshold são obtidas usando-se o teste de Multiplicador de Lagrange com correção para heterocedasticidade. Esse procedimento consiste em verificar se existe evidência para o efeito threshold, considerando-se a hipótese nula de sua inexistência e computando-se os p-valores via bootstrap.

Convém ademais ressaltar que o teste para efeito threshold foi aplicado de forma interativa até o ponto em que não houve mais evidência estatística da necessidade de novas subdivisões amostrais. Dito isso, os resultados encontrados para a divisão da amostra, entre os nós de decisão, estão sintetizados na Tabela 1, abaixo. Nessa Tabela, é apresentada a identificação de cada nó, os valores da estatística LM, o valor threshold e o intervalo de confiança. Por esse enfoque, vê-se que os resultados demonstraram a existência de cinco nós de decisão e de seis nós terminais. Os nós de decisão correspondem ao nó inicial e mais quatro outros obtidos nas interações realizadas.

criados após essa data.

5 O valor do Produto Interno Bruto, tanto em 1980 como em 2004, está em R \$ de 2000 na unidade de mil reais. 
Tabela 1: Decisão de divisão da amostra.

\begin{tabular}{c|c|c|c}
\hline \multirow{2}{*}{$\begin{array}{c}\text { Nó de } \\
\text { decisão }\end{array}$} & Teste LM & \multicolumn{2}{|c}{ Decisão de divisão } \\
\cline { 2 - 4 } & PIB 80 & $\begin{array}{c}\text { Valor } \\
\text { threshold }\end{array}$ & Intervalo de confiança \\
\hline PIB INICIAL & 70.9721 & 6.6368 & {$[6.4962 ; 6.7408]$} \\
\hline 1.2 & 6.9064 & 6.7545 & {$[6.7525 ; 9.0414]$} \\
\hline 2.2 & 10.1944 & 7.4857 & {$[6.8475 ; 9.0456]$} \\
\hline 3.1 & 12.3934 & 7.3521 & {$[6.7695 ; 7.4857]$} \\
\hline 3.2 & 10.6643 & 7.7498 & {$[7.6817 ; 7.7540]$} \\
\hline
\end{tabular}

O nível de significância utilizado foi de $95 \%$ e H0: não há divisão da amostra.

Fonte: Elaboração dos autores.

Um diagrama de árvore foi elaborado (Figura 1) contendo os nós de decisão e os nós terminais - os quadrados representam os nós de decisão e os círculos representam os nós terminais. As informações em cada quadrado representam a identificação do nó de decisão e o número de municípios nele contido. $O$ valor threshold é disposto nos ramais que saem de cada nó. Da mesma forma, a informação dentro do nó terminal representa sua identificação e o número de municípios contido em cada nó. Além disso, cabe ressaltar que, à esquerda descendente de cada nó de decisão, estão as observações com variável inferior ou igual ao valor threshold, e, à direita, estão as observações com variável maior que o valor threshold.

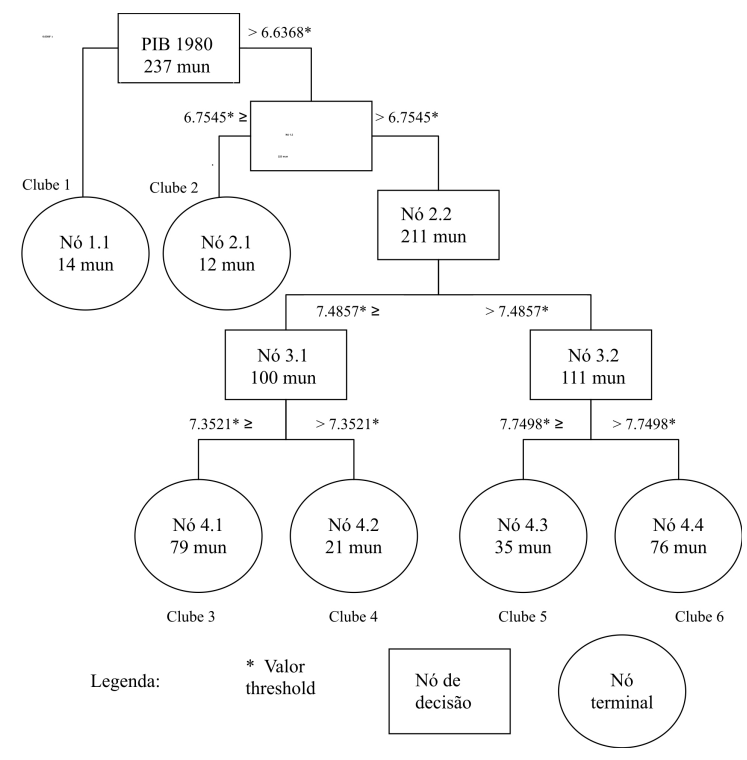

Figura 1: Diagrama de decisão do efeito threshold Fonte: Elaboração dos autores. 
No diagrama de árvore acima (Figura 1), pode-se observar a existência de cinco nós de decisão e de seis nós terminais. Isso implica a existência de seis grupos com diferentes padrões de crescimento econômico e distintas características socioeconômicas.

O nó terminal 1.1 corresponde ao clube de convergência 1 , que seria o mais pobre de toda a amostra, abrangendo 14 municípios com valor do PIB per capita inicial inferior ou igual a $\mathrm{R} \$ 762,65^{6}$. O nó terminal 2.1 corresponde ao clube de convergência 2, que abrange 12 municípios com PIB per capita inicial entre $\mathrm{R} \$$ 762,65 e $\mathrm{R} \$ 857,91$. Os nós terminais 4.1 e 4.2 correspondem, respectivamente, aos clubes de convergência 3 e 4, os quais são clubes intermediários. O clube 3 abrange 79 municípios com PIB per capita inicial entre $\mathrm{R} \$ 857,91$ e $\mathrm{R} \$ 1.559,47$, e o clube 4 abrange 21 municípios com PIB per capita inicial entre R $\$ 1.559,47$ e $\mathrm{R} \$ 1.782,37$. Os nós terminais 4.3 e 4.4 correspondem, respectivamente, aos clubes de convergência 5 e 6 , que são os mais ricos de toda a amostra. O clube 5 abrange 35 municípios com PIB per capita inicial entre $\mathrm{R} \$ 1.782,37$ e $\mathrm{R} \$ 2321,11$. Por fim, o clube 6, o mais rico de todos, abrange 76 municípios com PIB per capita inicial superior a $\mathrm{R} \$ 2321,11$.

\subsection{Análise dos nós terminais}

A Tabela 2, abaixo, apresenta os resultados das regressões de Mínimos Quadrados Ordinários (MQO) para cada um dos seis nós terminais e para a amostra total, ou seja, para todos os municípios da Amazônia Legal.

6 Esse valor é derivado da aplicação do antilog ao valor threshold. 
$\stackrel{N}{\circlearrowleft} \quad$ Tabela 2: Análise de regressão de MQO.

\begin{tabular}{|c|c|c|c|c|c|c|c|}
\hline & $\begin{array}{c}\text { Amazônia Legal } \\
\text { aa Legal }\end{array}$ & Clube 1 & Clube 2 & Clube 3 & Clube 4 & Clube 5 & Clube 6 \\
\hline Municípios & 237 & 14 & 12 & 79 & 21 & 35 & 76 \\
\hline Constante & $\begin{array}{l}3.985^{*} \\
(0.813)\end{array}$ & $\begin{array}{l}15.004 * \\
(1.900)\end{array}$ & $\begin{array}{l}-51.580^{*} \\
(19.242)\end{array}$ & $\begin{array}{c}2.066 \\
(1.990)\end{array}$ & $\begin{array}{l}10.896 \\
(9.660)\end{array}$ & $\begin{array}{l}29.741^{*} \\
(8.102)\end{array}$ & $\begin{array}{l}3.085^{*} \\
(0.877)\end{array}$ \\
\hline $\operatorname{Ln}(\mathrm{Y} / \mathrm{L})_{1980}$ & $\begin{array}{l}-0.776^{*} \\
(0.136)\end{array}$ & $\begin{array}{l}-2.302^{*} \\
(0.251)\end{array}$ & $\begin{array}{l}7.233 * \\
(2.865)\end{array}$ & $\begin{array}{l}-0.408 \\
(0.263)\end{array}$ & $\begin{array}{l}-1.414 \\
(1.294)\end{array}$ & $\begin{array}{l}-4.225^{*} \\
(1.092)\end{array}$ & $\begin{array}{l}-0.629 * \\
(0.121)\end{array}$ \\
\hline Ln (capital físico) ${ }_{i}$ & $\begin{array}{l}-0.389^{*} \\
(0.087)\end{array}$ & $\begin{array}{c}-0.343 * * \\
(0.188)\end{array}$ & $\begin{array}{l}-0.374 \\
(0.202)\end{array}$ & $\begin{array}{l}-0.332^{*} \\
(0.134)\end{array}$ & $\begin{array}{l}0.204 * \\
(0.096)\end{array}$ & $\begin{array}{l}-0.527 * \\
(0.153)\end{array}$ & $\begin{array}{c}-0.281 * \\
(0.098)\end{array}$ \\
\hline Ln (capital humano) ${ }_{i}$ & $\begin{array}{l}0.527^{*} \\
(0.124)\end{array}$ & $\begin{array}{c}0.298 \\
(0.482)\end{array}$ & $\begin{array}{c}1.467 * \\
(0.565)\end{array}$ & $\begin{array}{c}0.011 \\
(0.228)\end{array}$ & $\begin{array}{c}0.058 \\
(0.287)\end{array}$ & $\begin{array}{c}0.508 * \\
(0.199)\end{array}$ & $\begin{array}{l}0.622 * \\
(0.133)\end{array}$ \\
\hline $\mathrm{h}\left(n_{i}+\chi+d\right)$ & $\begin{array}{l}-0.034 \\
(0.042)\end{array}$ & $\begin{array}{l}0.450^{*} \\
(0.168)\end{array}$ & $\begin{array}{c}-0.717^{*} \\
(0.272)\end{array}$ & $\begin{array}{c}-0.026 \\
(0.057)\end{array}$ & $\begin{array}{c}-0.202^{* *} \\
(0.110)\end{array}$ & $\begin{array}{c}-0.031 \\
(0.076)\end{array}$ & $\begin{array}{c}-0.117^{* *} \\
(0.064)\end{array}$ \\
\hline $\mathbf{R}^{2}$ ajustado & 0.454 & 0.936 & 0.674 & 0.199 & 0.284 & 0.586 & 0.415 \\
\hline Resíduo de variância & 0.303 & 0.292 & 0.287 & 0.215 & 0.076 & 0.180 & 0.219 \\
\hline
\end{tabular}

* significantes a $5 \%$.

** significantes a $10 \%$.

Obs.: Os valores entre parênteses são os desvios padrões.

Fonte: Elaboração dos autores. 
Analisando-se a tabela acima, observa-se que, para a amostra total, isto é, para a Amazônia Legal, o coeficiente do logaritmo do PIB per capita inicial dos municípios apresentou-se significante e com sinal negativo esperado, portanto, indicando a existência de convergência entre todos os municípios. No entanto, pode observar-se que apenas o capital humano mostrou-se significante e com sinal positivo esperado, sendo importante para explicar o processo de convergência. A proxy utilizada para representar investimento em capital físico, ou seja, o Fundo de Participação dos Municípios (FPM), mostrou-se significante, porém, ao contrário do que se expectava, com sinal negativo e aparentemente atuando de uma maneira contrária ao processo de convergência. Portanto, existem indícios de convergência absoluta para o conjunto de municípios da Amazônia Legal.

Observando-se os resultados para os clubes com maior PIB per capita, clubes 5 e 6 , constata-se a existência de convergência dentro de cada um desses clubes de municípios. Verifica-se, também, que o capital humano mostrou-se importante na explicação do processo de crescimento dentro deles. Entretanto, a proxy escolhida para representar o investimento em capital físico (FPM), da mesma forma que para toda a amostra da Amazônia Legal, mostrou-se negativamente significante para o processo de convergência dentro de ambos os clubes.

Em relação aos clubes com menor PIB per capita, clubes 1 e 2, nota-se que o processo de convergência manifestou-se apenas dentro do clube 1 , no qual o capital físico também se mostrou significantemente negativo para a explicação do crescimento dos municípios, e o capital humano, diferentemente do que se verificou para os clubes mais ricos, mostrou-se insignificante para a explicação do processo de convergência. Dadas as condições socioeconômicas desse clube, era de se esperar que tanto o capital físico quanto o capital humano fossem importantes para explicar o seu processo de crescimento. Em relação ao clube 2, os resultados demonstram que o coeficiente do PIB per capita inicial é significantemente positivo, indicando que dentro do clube 2 houve divergência, ao invés de convergência. Ao contrário do clube 1, o capital humano mostrou-se significante e positivo para o processo de crescimento do clube, e o capital físico mostrou-se insignificante.

Já com relação aos clubes com PIB per capita intermediários, clubes 3 e 4, os resultados tornam evidente que os coeficientes dos PIB per capita iniciais não são significantes, indicando que esses clubes não apresentam nem convergência nem divergência. O capital humano, em ambos os clubes, é insignificante para explicar o processo de crescimento econômico. Já a proxy para capital físico resultou significantemente negativa para o clube 3 e, pela primeira e única vez, evidenciou-se significante e positiva para a explicação do processo de crescimento do clube 4 . 
Ainda com relação aos clubes intermediários, pode-se deduzir que as ausências tanto de convergência quanto de divergência sugerem que os municípios dentro desses dois clubes não estão migrando nem em direção aos clubes de municípios mais ricos, nem em direção aos clubes de municípios mais pobres. Diante disso, pode-se inferir que não estão migrando nem mesmo para uma mesma unidade dentro dos próprios clubes. Portanto, esses municípios pertencentes aos clubes 3 e 4 permanecem estagnados dentro dos próprios clubes, não sofrendo alterações no processo de crescimento do PIB per capita.

Em termos de localização geográfica, pode-se observar na figura apresentada abaixo a dispersão dos 237 municípios por clubes de convergência no espaço geográfico da Amazônia Legal. Observa-se que os clubes 1 e 2, os mais pobres da amostra, são formados em quase sua totalidade pelos municípios do Maranhão, já os clubes de renda per capita intermediária, clubes 3 e 4, são formados na maior parte por municípios do Maranhão, Pará, Amazonas, Tocantins e Acre. Por fim, os clubes 5 e 6 , os mais ricos da amostra, são formados principalmente pelos municípios dos Estados do Mato Grosso, Pará, Amazonas e Tocantins e, em menor parte, pelos municípios de Rondônia, Maranhão, Acre, Roraima e Amapá.

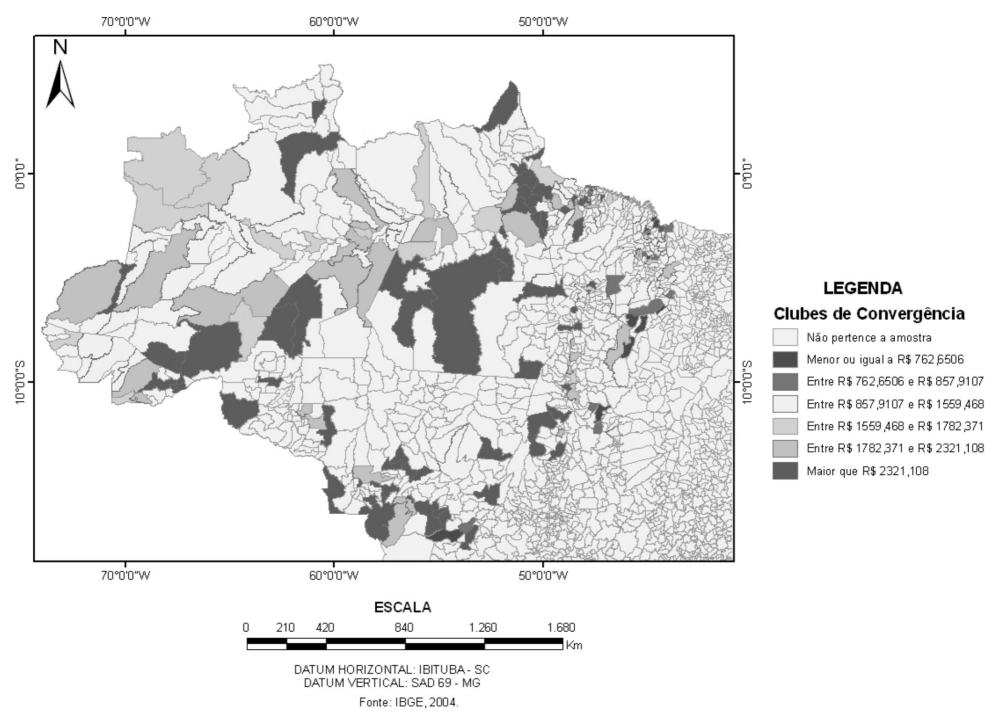

Figura 2: Dispersão espacial dos municípios de acordo com a classificação dos

Fonte: Elaboração dos autores. clubes de convergência. 


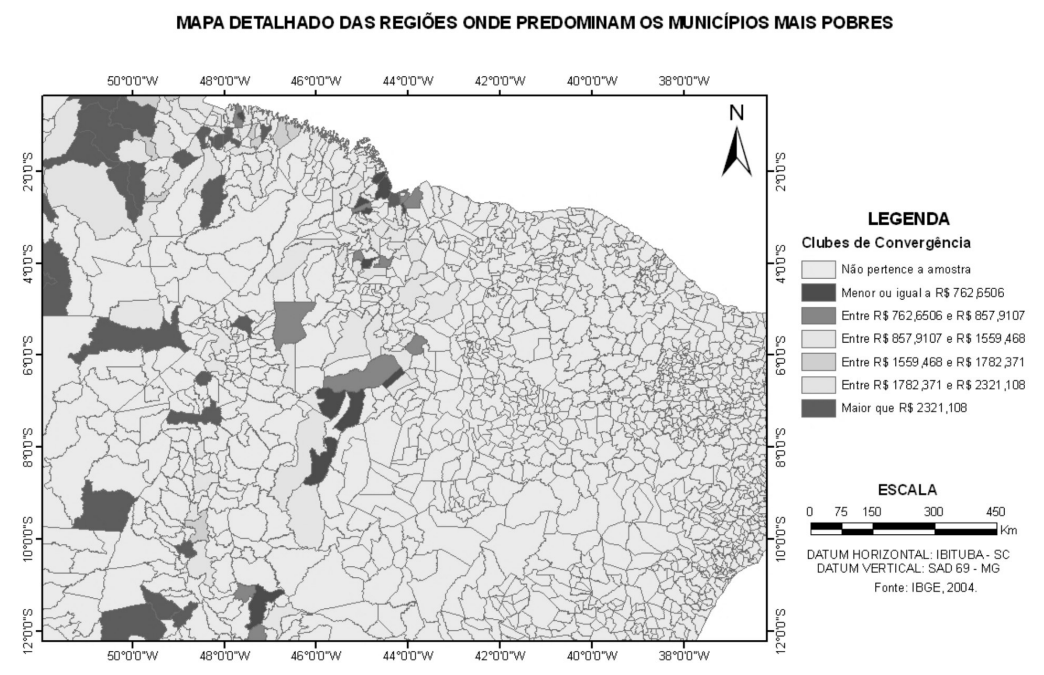

Fonte: Elaboração dos autores.

Considerando-se todas as regressões dos clubes de convergência, observa-se que a proxy utilizada para capital humano comportou-se como significante apenas para três clubes de convergência, dois dos três clubes abrangendo os municípios mais ricos da amostra e somente um correspondendo aos municípios mais pobres, justamente o clube que apresentou divergência. Já a proxy para capital físico apresentou-se significante e positiva somente para um clube intermediário que não retratou nem convergência, nem divergência. Em relação aos outros cinco clubes, mostrou-se significantemente negativa para a explicação do processo de crescimento econômico de quatro clubes e insignificante para um clube mais pobre, o qual apresentou divergência.

De uma forma geral, esperava-se que a acumulação de capital humano (educação) e o investimento em capital físico, o qual foi representado pelo FPM, seriam importantes para explicar o processo de crescimento dos municípios, principalmente para os clubes mais pobres.

Em relação ao capital humano, conforme Krueger and Lindahl (2001), esses resultados aparentemente contraditórios podem advir da especificação errada da relação entre crescimento econômico e nível de educação.

Benhabib e Spiegel (1994) chegaram a resultados que indicavam insignificância estatística do crescimento do capital humano para explicar variações na taxa de crescimento do produto per capita dos países que mais acumularam capital humano no período de 1965 a 1985. Somente quando fizeram uma nova 
especificação de modelo, com uma nova medida de capital humano, obtiveram resultados melhores. Mas, mesmo assim, não encontraram uma relação significativa entre capital humano e crescimento econômico.

Os resultados obtidos por Lau et al. (1993) sobre a economia brasileira no período de 1970 a 1980 indicavam um efeito estimado, estatisticamente significante, de 0,21 da média de educação sobre o crescimento do produto, pelo que um ano adicional na média de educação aumentaria o produto em aproximadamente $21 \%$. Contudo, os autores alertaram que a evidência desse amplo efeito da média de educação poderia dever-se à existência de um efeito limiar de uma média de educação entre 3 e 4 anos de ensino.

No trabalho de Nunes e Peres Nunes (2005) sobre os estados brasileiros para o período de 1937 a 1999, foi utilizado o número de matrículas do segundo grau como proxy para capital humano nos testes de convergência. Segundo esses autores, a escolaridade tem favorecido os estados mais ricos, pois, quanto maiores os níveis de renda per capita dos estados, maior o papel da escolaridade no nível de crescimento. Além disso, segundo os autores, verificou-se uma grande discrepância entre os gastos per capita dos estados. Esse fato contribui para dificultar uma equalização dos gastos em educação por todo o país.

Em relação ao capital físico, ou mais precisamente ao Fundo de Participação Municipal, que é uma modalidade de transferência constitucional de recursos financeiros da União para os municípios, prevista na Constituição Federal (CF).

De acordo com o artigo 159, inciso I, alínea "a" e "b", da CF, o FPM é constituído de 22,5\% da arrecadação líquida (arrecadação bruta deduzida de restituições e incentivos fiscais) do Imposto sobre a Renda e Proventos de Qualquer Natureza (IR) e do Imposto sobre Produtos Industrializados (IPI). A distribuição dos recursos aos municípios é feita de acordo com o número de habitantes. São fixadas faixas populacionais, cabendo a cada uma delas um coeficiente individual. O mínimo é 0,6 para municípios com até 10.188 habitantes, e o máximo é 4,0 para aqueles acima de 156 mil. Os coeficientes dos municípios são fixados de acordo com o disposto na Lei n. ${ }^{\circ}$ 5.172/66 (Código Tributário Nacional), com as alterações do Decreto-Lei n. ${ }^{\circ} 1.881 / 81$, e nas Leis Complementares n. ${ }^{\circ} 59 / 88$, n. $^{\circ}$ 62/89, n. ${ }^{\circ} 71 / 92$ e n. $^{\circ} 74 / 93$. No caso das capitais e dos municípios participantes da reserva criada pelo Decreto-Lei n. ${ }^{\circ} 1.881 / 81$ com coeficiente 4,0, utiliza-se, também, a renda per capita do respectivo estado (BRASIL, 2008; TRIBUNAL DE CONTAS DA UNIÃO, 2008).

Do total de recursos, $10 \%$ são destinados às capitais, $86,4 \%$, aos demais municípios, e os 3,6\% restantes vão para um fundo de reserva que beneficia os municípios com população superior a 142.633 habitantes (coeficiente de 3.8), 
excluídas as capitais (BRASIL, 2008; TRIBUNAL DE CONTAS DA UNIÃO, 2008).

Bremaeker (2004) fez severas críticas às distorções introduzidas na distribuição do Fundo de Participação dos Municípios pela sistemática adotada pela Lei Complementar n. ${ }^{\circ}$ 91, de 1997, e mantida pela Lei Complementar n. ${ }^{\circ}$ 106, de 2001. Esse autor questionou a metodologia de cálculo dos repasses dos recursos do FPM, na forma prevista na Lei Complementar n. ${ }^{\circ}$ 91, de 1997, a qual introduziu os redutores dos coeficientes do FPM com implicações para os anos de 1999, 2000, 2001, 2002 e 2003. Com base em dados dos municípios do Estado de Rondônia (cinquenta e um municípios, exceto o da capital) contemplando uma ampla variedade de situações, pelo fato de uma parcela considerável dos municípios desse estado (vinte) estar sujeita ao redutor do FPM sob diferentes intensidades, o autor alegou que a lei prejudicava os municípios sujeitos ao redutor do FPM e beneficiava os não sujeitos ao redutor.

Nunes e Peres Nunes (2005) analisaram o papel dos Fundos de Participação dos Estados (FPE) na convergência da renda per capita dos estados brasileiros no período de 1937 a 1999. Conforme os autores, no Brasil, a arrecadação tributária é predominantemente centralizada, e as transferências fiscais são bastante elevadas, respondendo por boa parte da descentralização fiscal. Esses repasses da União para estados e municípios são realizados por meio do FPE e do FPM. Segundo os autores, deve ser ressaltado não somente o fato de que o FPE é mal distribuído - por conseguinte, alguns estados pobres recebem, em termos per capita muito mais do que os estados ricos, ou seja, uma porcentagem muito maior do que aquela que os separa em termos de receita do ICMS per capita-, mas também o fato de que estados pobres recebem transferências desproporcionalmente desiguais, do que resultam severas distorções. No entanto, segundo os autores, apesar desses problemas apontados, os Fundos de Participação dos Estados contribuíram para a convergência de renda e para a redução das desigualdades sociais dos estados no período de 1969 a 1999.

Nos testes cross-section de Barro (1991) para 98 países, compreendendo o período de 1960 a 1985, o citado autor mostrou, com base em seus resultados empíricos, que o crescimento econômico apresentou-se inversamente relacionado com a parte do consumo governamental no Produto e insignificantemente relacionado para a parte de investimento público. Segundo Barro (1991), uma possível interpretação desses resultados residiria no fato de o consumo governamental introduzir distorções na economia, como altas taxas de impostos, além de não promover um estímulo eficiente para investimento e crescimento econômico. 
Considerando-se essas observações de Barro (1991), sobretudo as questões levantadas acima, e atentando para o fato de que o FPM é uma transferência de recursos da União para os municípios, ou seja, corresponde a recursos públicos, observa-se facilmente que o FPM pode, no máximo, ser considerado uma proxy representativa de investimento público em capital físico, pois o investimento total é composto pelo conjunto de investimentos privados e públicos. Assim, uma interpretação plausível para a relação negativa entre o crescimento econômico dos municípios da Amazônia Legal e a acumulação em capital físico (acumulação que neste trabalho deve ser entendida como derivada de investimento público) seria a de que o investimento público introduziu distorções nessa economia. Uma outra interpretação seria com relação à efetiva e eficiente aplicação na acumulação de capital dos recursos públicos advindos do FPM. Esses recursos poderiam estar sendo aplicados, não necessariamente na acumulação de capital físico dos municípios, como investimento em infraestrutura, bens públicos e semipúblicos etc., mas em outras despesas e atividades. Outra importante observação, como se sabe, é que as economias subdesenvolvidas têm como uma de suas características marcantes a corrupção, em razão da qual os recursos públicos são desviados de seus verdadeiros fins para atender a anseios particulares de uma parcela da população. Impende especular, portanto, se o resultado empírico obtido pode estar refletindo esse fato. Além do mais, corroborando essa assertiva, é possível também a identificação de um efeito rent-seeking na apropriação, por uma minoria, dos benefícios da aplicação dos recursos públicos, como demonstrou Diniz (2005).

\section{CONSIDERAÇÕES FINAIS}

Neste trabalho, objetivou-se realizar uma investigação empírica sobre a existência de um processo de convergência de renda entre os municípios da Amazônia Legal no período de 1980 a 2004, levando-se em consideração a possibilidade de existência de grupos de municípios com características socioeconômicas diferentes.

Com base nos trabalhos de Mankiw, Romer e Weil (1992) e Durlauf e Johnson (1995), buscou-se investigar se investimentos em capital físico e acumulação em capital humano seriam importantes na caracterização das performances socioeconômicas dos municípios da Amazônia Legal.

Utilizando-se dados do Instituto de Pesquisa Econômica Aplicada (IPEA), envolvendo uma amostra de 237 municípios da Amazônia Legal, examinou-se a hipótese de convergência para um único ou múltiplos regimes de convergência no período de 1980 a 2004 para a Amazônia Legal, por meio do modelo Threshold proposto por Hansen (2000). 
Os resultados indicaram a existência de seis grupos de municípios com características socioeconômicas distintas, ou seja, seis clubes de convergência. Já dentro de cada clube, os resultados das regressões de Mínimos Quadrados Ordinários (MQO) apontaram que a hipótese de convergência verifica-se dentro dos clubes extremos, os quais correspondem a dois clubes ricos e a um clube pobre. Entretanto, não se verificou convergência dentro dos clubes de renda intermediária, além de ser constatada divergência dentro do segundo clube mais pobre da região.

Os resultados mostraram que a proxy capital humano, aqui representada pelos anos médios de estudo de pessoas com 25 anos ou mais, foi significante para influenciar o processo de crescimento dos clubes mais ricos, porém mostrouse significante para apenas um clube mais pobre, corroborando, dessa forma, o pressuposto da existência de um efeito limiar para capital humano sugerido no trabalho de Lau et al. (1993) e os resultados do trabalho de Freitas e Bacha (2004), no qual esses autores levaram em consideração o efeito limiar para o capital humano.

Os resultados também indicaram que o capital físico, aqui representado pela fração média do PIB correspondente ao Fundo de Participação dos Municípios, foi significantemente negativo para a explicação do processo de crescimento da maioria dos clubes. Essa variável somente se evidenciou significante e positiva para um clube de renda intermediária que não apresentou convergência. Esses resultados parecem corroborar o pressuposto de Barro (1991), que encontrou em seu trabalho, sobre o crescimento econômico de 98 países, resultados insignificantes para investimento público e resultados significantemente negativos para o consumo (gastos) do governo. Esse autor sugeriu que os resultados ruins, oriundos da ação do agente público, poderiam estar ligados à falta de estímulos eficientes para o investimento e o crescimento econômico, assim como a distorções inseridas na economia por meio da intervenção pública.

Por fim, vale destacar que a alavancagem e a sustentação do processo de crescimento e desenvolvimento de uma economia devem ser acompanhadas tanto de capital humano qualificado, quanto de investimentos eficientes em capital físico e poupança interna.

Infere-se, dessa concepção, que os resultados encontrados neste trabalho mostram-se importantes na medida em que se identificaram grupos de economias com características socioeconômicas distintas, o que propiciou uma melhor visão do espaço econômico da Amazônia Legal. Por outro lado, estes estudos são capazes de fornecer uma ferramenta de análise para futuras políticas de desenvolvimento regional, além de também virem a servir como uma primeira referência para futuros debates sobre convergência de renda na região. 


\section{REFERÊNCIAS}

AGHION, Philippe; HOWITT, Peter. A model of growth through creative destruction.Econometrica, v. 60, n. 2, p. 323-351, mar. 1992.

ALEXANDRE, Michel; BIDERMAN, Ciro; LIMA, Gilberto Tadeu. Distribuição regional do crédito bancário e convergência no crescimento estadual brasileiro. 2004. Disponível em: <http://www.anpec.org.br/encontro2004/ artigos/A04A124.pdf>. Acesso em: 10 jan. 2008.

ALVES, L. F; FONTES, R. Clubes de convergência entre os municípios de Minas Gerais. 2000. Disponível em: <http://www.cedeplar.ufmg.br/ diamantina2000/2000/fontes.pdf>. Acesso em: 2 jan. 2008.

AZARIADIS, C.; DRAZEN, A. Threshold externalities in economic development. The Quarterly Journal of Economics, v. 105, n. 2, p. 501-526, 1990.

AZZONI, Carlos R. Crescimento econômico e convergência das rendas regionais: o caso brasileiro à luz da Nova Teoria do Crescimento. In: ENCONTRO NACIONAL DE ECONOMIA, 22., 1994, Florianópolis. Anais... Florianópolis: ANPEC, 1994, v. 1. p. 185-205.

AZZONI, Carlos R. Concentração regional e dispersão das rendas per capita estaduais: análise a partir de séries históricas estaduais de PIB, 1939-1995. Estudos Econômicos, v. 27, n. 3, p. 341-393, set./dez. 1997.

AZZONI, C. R.; MENEZES-FILHO, N.; DE MENEZES, T. A.; SILVEIRANETO, R. Geography and income convergence among Brazilian States. Inter American Development Bank, 2000.

BAUMOL, W. J. Productivity growth, convergence, and welfare: what the long-Run Data Show. The American Economic Review, v. 76, n. 5, p. 1072-1085, 1986.

BAUMOL, W. J.; WOLFF, E. N. Productivity growth, convergence, and welfare: reply. The American Economic Review, v. 78, n. 5, p. 1155-1159, 1988.

BAROSSI FILHO, Milton; AZZONI, Carlos R. A time series analysis of regional income convergence in Brazil. In: FÓRUM BNB DE DESENVOLVIMENTO, ENCONTRO REGIONAL DE ECONOMIA, 8., 2003, Fortaleza. Anais... Fortaleza: BNB; ANPEC, 2003. p. ...-...

BARRO, R. J. Economic growth in a cross section of countries. The Quarterly Journal of Economics, v. 106, n. 2, p. 407-433, 1991. 
BARRO, Robert; SALA-I-MARTIN, Xavier. Convergence. The Journal of Political Economy, v. 100, n. 21, p. 223-251, apr. 1992.

BARRO, Robert; SALA-I-MARTIN, Xavier. Economic Growth. New York: McGraw-Hill, 1995a.

BARRO, Robert; SALA-I-MARTIN, Xavier. Technological difusion, convergence and growth. oct. 1995b. CEPR Discussion Paper n. 1255.

BASSANINI, A.; SCARPETTA, S. Does human capital matter for growth in OECD countries? A pooled meangroup approach. Economics Letters, v. 74, n. 3, p. 399-405, 2002.

BECKER, G. S. Human capital: a theoretical and empirical analysis, with special reference to education. 3d ed. Chicago: University of Chicago Press, 1993. 412 p. BENHABIB, J.; SPIEGEL, M. M. The role of human capital in economic development evidence from aggregate cross-country data. Journal of Monetary Economics. v. 34, n. 1, p. 143-173, 1994.

BERNARD, A. B.; DURLAUF, S. N. Interpreting tests of the convergence hypothesis. Cambridge, MA: National Bureau of Economic Research, 1994. Technical Working Paper No. 159.

BERNARD, A. B.; DURLAUF, S. N. Convergence in international output. Journal of Applied Econometrics, v. 10, n. 2, p. 97-108, 1995.

BERNARD, A. B.; JONES, C. I. Comparing apples to oranges: productivity convergence and measurement across industries and countries. The American Economic Review, v. 86, n. 5, p. 1216-1238, 1996.

BHANOJ I RAO, V. V.; THANGAVELU, S. M. Do poor countries tend to grow faster than rich countries? Applied Economics Letters, n. 7, p. 629-632, 2000.

BISHOP, J. A.; FORMBY, J. P.; THISTLE, P. D. Convergence of the south and non-south income distributions, 1969-1979. The American Economic Review, v. 82 , n. 1 , p. $262-272,1992$.

BRASIL. Ministério da Educação. Secretaria de Educação Superior. Expansão: Amazônia Legal. Disponível em: <http://portal.mec.gov.br/sesu/index.php?o ption $=$ content\&task $=$ view\&id $=653 \&$ Itemid $=300>$. Acesso em: 25 out. 2007 .

BRASIL. Presidência da República. Controladoria Geral da União. Portal da 
Transparência: Fundo de Participação dos Municípios. Disponível em: <http:/ / www.portaltransparencia.gov.br/PortalTransparenciaGlossario.asp > . Acesso em: 28 jan. 2008.

BRASIL. Presidência da República. Sistema de Proteção da Amazônia. Amazônia Legal: legislação sobre a criação da Amazônia Legal. Disponível em: <http:// www.sipam.gov.br/portal/index.php?option $=$ com_content\&task $=$ view\&id $=58$ \&Itemid=37>. Acesso em: 25 out. 2007.

BREMAEKER, F. E. J. Distorções introduzidas na distribuição do fundo de participação dos municípios. Rio de Janeiro: Instituto Brasileiro de Administração Municipal, 2004. Série de Estudos Especiais, n. 73.

CAPOLUPO, R. Convergence in recent growth theories: a survey. Journal of Economic Studies, v. 25, n. 6, p. 496-537, 1998.

CASS, D. Optimum Growth in an aggregative model of capital accumulation. The Review of Economic Studies, v. 32, n. 91, p. 233-240, July 1956.

CHOI, H.; LI, H. Economic development and growth convergence in China. The Journal of International Trade \& Economic Development, v. 9, n. 1, p. 37-54, 2000.

COULOMBE, S.; LEE, F. C. Convergence across Canadian provinces, 1961 to 1991. The Canadian Journal of Economics, v. 28, n. 4a, p. 886-898, 1995.

DE LA FUENTE, A. On the sources of convergence: a close look at the Spanish regions. European Economic Review, v. 46, p. 569-599, 2002.

DE LONG, J. B. Productivity growth, convergence, and welfare: comment. The American Economic Review, v. 78, n. 5, p. 1138-1154, 1988.

DESTINOBLES, A. G. El modelo de Mankiw, Romer y Weil (1992) en el Programa de Investigación Neoclásico. Revista de la Facultad de Economía, BUAP, año X, n. 30, p. 5-31, sept./dic. 2005.

DINIZ, M. B. Contribuições ao estudo da desigualdade de renda entre os estados brasileiros. 2005. ... f. Tese (Doutorado em Economia ) - Universidade Federal do Ceará, Fortaleza, 2005.

DRENNAN, M. P.; LOBO, J. A simple test for convergence of metropolitan income in the United States. Journal of Urban Economics, v. 46, p. 350-359, 1999.

DURLAUF, S. N.; JOHNSON, P. Multiple regimes and cross-country growth 
behaviour. Journal of Applied Econometrics, London, v. 10, n. 4, p. 365-384, oct. 1995.

FERREIRA, Afonso Henrique B. Evolução recente das rendas per capita estaduais no Brasil: o que a nova evidência mostra. Revista Econômica do Nordeste, Fortaleza, v. 27, n. 3, p. 363-374, jul./set. 1996.

FERREIRA, A. H. B.; DINIZ, C. C. Convergencia entre las rentas per capita estaduales en Brasil. EURE-Revista Latinoamericana de Estudios Urbano Regionales, Santiago, v. 21, n. 62, p. 17-31, 1995a.

FERREIRA, Afonso Henrique B.; DINIZ, Clélio Campolina. Convergência entre as rendas per capita estaduais no Brasil. Revista de Economia Política, v. 15, n. 4, p. 38-56, out./dez. 1995b.

FERREIRA, P. C. G.; ELLERY JÚNIOR, R. G. Convergência entre a renda per capita dos estados brasileiros. Revista de Econometria, SBE, v. 16, n. 1, p. 83103, abr. 1996.

FREITAS, C. A.; BACHA, C. J. C. Contribuição do capital humano para o crescimento da agropecuária brasileira - período de 1970 a 1996. Revista Brasileira de Economia, v. 58, n. 4, p. 533-557, out./dez. 2004.

GALOR, O. Convergence? Inferences from theoretical models. The Economic Journal, New York, v. 106, n. 437, p. 1056-1069, feb. 1996.

GALVEZ, J. C. P. La convergencia económica en Andalucía (1965-1995). In: ENCUENTRO INTERNACIONAL SOBRE POBREZA, DESIGUALDAD Y CONVERGENCIA, 2., 2006. Actas... Disponível em: < http://www.eumed. net/eve/resum/o6-03/jcpg.htm>. Acesso em: 15 dez. 2007.

GONDIM, J. L. B.; BARRETO, F. A.. O uso do núcleo estocástico para identificação de clubes de convergência entre estados e municípios brasileiros. In: ENCONTRO NACIONAL DE ECONOMIA, 32., 2004, João Pessoa. Anais eletrônicos... Disponível em: < http://www.anpec.org.br/encontro2004/artigos/ A04A053.pdf>. Acesso em: 26 out. 2007.

GONDim, J. L. B., BARretO, F. A.; CARVALHO, J. R. Condicionantes de Clubes de Convergência no Brasil. Estudos Econômicos, São Paulo, v. 37, n. 1, p. 71-100, jan./mar. 2007.

GROLLI, P. A.; OLIVEIRA, C. A.; JACINTO, P. A. Crescimento econômico e convergência com a utilização de regressões quantílicas: um estudo para os municípios do Rio Grande do Sul (1970-2001). In: ENCONTRO DE 
ECONOMIA GAÚCHA, 3., 2006, Porto Alegre. Anais... Porto Alegre: PUC, 2006, v. 1. Disponível em: <http://www.anpec.org.br/encontro2006/artigos/ A06A014.pdf>. Acesso em: 15 dez. 2007.

GROSSMAN, Gene M. (Ed.). Economic growth: theory and evidence. Hants, UK: Edward Elgar, 2000, v. 1. (The International Library of Critical Writings in Economics series, v. 68).

GROSSMAN, Gene M.; HELPMAN, E. Quality ladders in the theory of growth. The Review of Economic Studies, v. 58, n. 1, p. 43-61, jan. 1991.

HANSEN, B. E. Sample splitting and threshold estimation. Econometrica, v. 68, n. 3, p. 575-603, 2000.

HOBIJN, B.; FRANSES, P. H. Are living standards converging? Structural Change and Economic Dynamics, v. 12, n. 2, p. 171-200, July 2001.

INSTITUTO DE PESQUISA ECONOMICA APLICADA. Dados dos municípios da Amazônia Legal. Disponível em: < http://www.ipeadata.gov. br>. Acesso em: 3 jan. 2008.

ISLAM, N. Growth empirics: a panel data approach. The Quarterly Journal of Economics, v. 110, n. 4, p. 1127-1170, 1995.

JONES, C. Introdução à teoria do crescimento econômico. Rio de Janeiro: Campus, 2000.

JONES, C. I. On the evolution of the world income distribution. The Journal of Economic Perspectives, v. 11, n. 3, p. 19-36, 1997.

KOOPMANS, Tjalling C. On the concept of optimal economic growth. In: PONTIFICACIA ACADEMIA SCIENTIARUM. The econometric approach to development planning. Amsterdam: North Holland, 1965. p. 225-287.

KRUEGER, A. B.; LINDAHL, M. Education for growth: why and for whom? Journal of Economic Literature, v. 39, n. 4, p. 1101-1136, 2001.

LAU, L. J.; JAMISON, D. T.; LIU, S.; RIVKIN, S. Education and economic growth: some cross-sectional evidence from Brazil. Journal of Development Economics, v. 41, n. 1, p. 45-70, June 1993.

LAURINI, M.; ANDRADE, E.; PEREIRA, P. L. V. Clubes de convergência de renda para os municípios brasileiros: uma análise não-paramétrica. São Paulo: Ibmec, 2003. Insper Working Paper, WPE 048. 
LUCAS JUNIOR, R. E. On the mechanics of economic development. Journal of Monetary Economics, n. 22, p. 3-42, 1988.

MAHAR, D. J. Desenvolvimento econômico da Amazônia: uma análise das políticas governamentais., Rio de Janeiro: IPEA; INPES, 1978. Relatório de pesquisa n. 39 .

MANKIW, N. G.; ROMER, D.; WEIL, D. N. A contribution to the empirics of economic growth. The Quarterly Journal of Economics, v. 107, n. 2, p. 407437, 1992.

MARTINEZ COLL, J. C. El crecimiento económico. In: MARTINEZ COLL, J. C. La economía de mercado, virtudes e inconvenientes. 2001. Disponível em: <http://www.eumed.net/cursecon/18/convergencia.htm>: Acesso em: 15 dez. 2007.

MENEZES, T. A; AZZONI, C. R. Convergência de renda real e nominal entre as regiões metropolitanas brasileiras: uma análise de dados de painel. In: ENCONTRO NACIONAL DE ECONOMIA, 28., 2000, Campinas. Anais..., Campinas: ANPEC, 2000.

NUNES, R. C.; PERES-NUNES, S. O papel dos fundos de participação dos estados-FPE na convergência da renda per capita dos estados brasileiros. Revista de Economía y Estadística, v. 43, p. 89-103, 2005.

OLIVEIRA JUNIOR, J. N.; CASTELAR, I.; FERREIRA, R. T. Convergência microrregional no setor agrícola usando um modelo Threshold. 2007. Disponível em:<http://www.anpec.org.br/encontro2007/artigos/A07A123. pdf $>$. Acesso em: 3 jan. 2008.

PEROBELLI, F. S.; FARIA, W. R.; FERREIRA, P. G. C. Análise de convergência espacial do pib per capita em Minas Gerais: 1975-2003, 2006. Disponível em: <http://www.bnb.gov.br/content/aplicacao/eventos/forumbnb2006/docs/ analise_de_convergencia.pdf $>$. Acesso em: 27 out. 2007.

PÔRTO-JÚNIOR, S. S.; RIBEIRO, E. P. Dinâmica espacial da renda per capita e crescimento entre os municípios da região Nordeste do Brasil: uma análise markoviana. 2003. Disponível em: <http://www.bnb.gov.br/content/ aplicacao/publicacoes/ren-numeros_publicados/docs/ren2003_v34_n3_a3.pdf>. Acesso em: 3 jan. 2008.

PRITCHET'T, L. Divergence, Big Time. Journal of Economic Perspectives, v. 11, n. 3, p. 3-17, 1997. 
QUAH, Danny. International patterns of growth: I. Persistence in crosscountry disparities. London School of Economics, 1992. Working Paper.

QUAH, Danny. Empirical cross-section dynamics in economic growth. European Economic Review, v. 37, p.426-434, 1993a.

QUAH, Danny. Galton's fallacy and tests of the convergence hypothesis. Scandinavian Journal of Economics, v. 95, n. 4, p. 427-443, 1993 b.

RAMSEY, Frank P. A mathematical theory of saving. Economic Journal, v. 38, n. 152 , p. 543-559, dec. 1928.

RAY, Debraj. Economía del desarrollo. Tradução para o espanhol de Maria Esther Rabasco. Barcelona: Antonio Bosch, 2002.

ROMER, P.M. Increasing returns and long-run growth. The Journal of Political Economy, v. 94, n. 5, p. 1002-1037, 1986.

SCHULTZ, T. W. Investment in Human Capital. The American Economic Review, v. 51, n. 1, p. 1-17, 1961.

SCHWARTSMAN, A. Convergence across Brazilian states. São Paulo: IPE; USP, 1996. Texto para discussão interna, n. 2.

SHIOJI, E. Composition effect of migration and regional growth in Japan. Journal of the Japanese and International Economics, n. 15, p. 29-49, 2001.

SOUZA, N. J.; PORTO-JÚNIOR, S. S. Crescimento regional e novos testes de convergência para os municípios da região Nordeste do Brasil. Texto para discussão, 2002. Disponível em: < http://www.ufrgs.br/ppge/pcientifica/2002_11. pdf $>$. Acesso em: 2 jan. 2008.

TRIBUNAL DE CONTAS DA UNIÃO. Fundo de Participação dos Municípios. Disponível em: <http://www.tcu.gov.br/Institucional/ Competências/Fundos.html>. Acesso em: 27 jan. 2008.

VERGOLINO, J. R.; GOMES, G. M. Metamorfoses da economia amazônica. In: ARMANDO, D. M. (Org.). A Amazônia e seu banco. Manaus: Valer, 2002. p. $245-277$. 